\title{
Adverse Outcomes Associated with Pre-Existing and New-Onset Atrial Fibrillation in Patients with Acute Coronary Syndrome: A Retrospective Cohort Study
}

\author{
Chun-Li Wang $\cdot$ Pei-Chun Chen $\cdot$ Hsiao-Ting Juang $\cdot$ Chee-Jen Chang
}

Received: September 19, 2018 / Published online: April 17, 2019

(C) The Author(s) 2019

\begin{abstract}
Introduction: Atrial fibrillation (AF) often occurs in patients with acute coronary syndrome (ACS). It remains unclear whether preexisting or new-onset AF confers different risk in patients with ACS.
\end{abstract}

Enhanced Digital Features To view enhanced digital features for this article go to https://doi.org/10.6084/ m9.figshare.7958006.

C.-L. Wang · C.-J. Chang

Cardiovascular Department, Internal Medicine, Chang Gung Memorial Hospital, Linkou Medical Center, Taoyuan, Taiwan

C.-L. Wang · C.-J. Chang

School of Medicine, Chang Gung University,

Taoyuan, Taiwan

P.-C. Chen · H.-T. Juang

Clinical Informatics and Medical Statistics Research Center, Chang Gung University College of

Medicine, Taoyuan, Taiwan

P.-C. Chen

Department of Public Health, China Medical

University, Taizhong, Taiwan

C.-J. Chang

Research Services Center for Health Information, Chang Gung University, Taoyuan, Taiwan

\section{C.-J. Chang ( $\square)$}

Graduate Institute of Clinical Medicine, Chang

Gung University, Taoyuan, Taiwan

e-mail: cjchang@mail.cgu.edu.tw
Methods: We conducted a retrospective cohort study using Taiwan's National Health Insurance Research Database. Patients who were hospitalized with a primary diagnosis of ACS from 2005 to 2009 were studied. Major outcomes were mortality, heart failure, and combined ischemic stroke/systemic embolism (IS/SE). The date of the first ACS diagnosis was defined as the index date. Pre-existing AF was defined as AF occurring before the index date. New-onset AF was defined as AF that started after or at the same time as the ACS diagnosis.

Results: Among 6663 patients with ACS, 488 (7.3\%) had pre-existing AF and 479 (7.2\%) had new-onset AF. Compared to patients with preexisting $\mathrm{AF}$, those with new-onset $\mathrm{AF}$ were younger, less likely to have co-morbidities, and more likely to receive evidence-based therapy. The un-adjusted risks of adverse outcomes in both groups were similar. Compared to pre-existing AF, new-onset AF was significantly associated with a higher adjusted risk of death (hazard ratio 1.27, 95\% confidence interval 1.06-1.52) and IS/SE (hazard ratio 1.49, 95\% confidence interval 1.01-2.20). The significant associations between new-onset $\mathrm{AF}$ and adverse outcomes were more likely to be observed in elderly patients with ACS.

Conclusions: New-onset AF during ACS was associated with a significantly increased risk of adverse outcomes, especially in the elderly patients. 
Keywords: Acute coronary syndrome; Atrial fibrillation; Heart failure; Ischemic stroke; Mortality; Systemic embolism

\section{INTRODUCTION}

Atrial fibrillation (AF) is a frequently observed arrhythmia in patients with acute coronary syndrome (ACS) $[1,2]$. AF can occur before the onset of ACS (pre-existing AF) or can be induced or exacerbated by increased sympathetic stimulation, ongoing myocardial ischemia or infarction, or worsening heart failure (HF) after ACS (new-onset AF) [3, 4]. In the setting of ACS, $\mathrm{AF}$ portends a worse prognosis compared to those in normal sinus rhythm [5-7]. However, it remains unclear whether new-onset and preexisting AF confer different risks in patients with ACS [1, 4, 8-11]. Some studies showed that pre-existing AF portends higher mortality risks than new-onset AF in patients with ACS $[1,11]$. However, other studies demonstrated that newonset $\mathrm{AF}$ rather than pre-existing $\mathrm{AF}$ was independently associated with worse outcomes in patients with ACS $[4,8-10]$. The aim of the present study was to analyze the prevalence, clinical features, and prognosis of different types of AF (pre-existing and new-onset AF) in patients who were hospitalized for the first time with a primary discharge diagnosis of ACS. In addition, we also evaluated the effects of age and sex on the risk of adverse outcomes associated with new-onset and pre-existing AF in patients with ACS.

\section{METHODS}

We conducted a retrospective cohort study using data from the National Health Insurance Research Database (NHIRD) released by the Taiwan National Health Research Institutes. We used a longitudinal dataset that contains all medical claim data and death registry for 2 million beneficiaries randomly sampled from 25.68 million patients enrolled in the universal National Health Insurance program in Taiwan. In the NHIRD, the identification numbers of the patients are encrypted to protect their privacy, but the encrypting procedure is consistent so that a linking of claims belonging to the same patient is feasible and can be followed longitudinally. Patients who were hospitalized for the first time with a primary discharge diagnosis of ACS from 2005 to 2009 were recruited. To restrict the analysis to patients with a first ACS event, we retrospectively searched claims back to 2000 to exclude patients who had a previous admission diagnosis of ACS. The date of the first ACS diagnosis was defined as the index date. Patients with an ACS diagnosis before the index date of ACS $(n=499)$ were excluded from the study. Patients younger than 18 years $(n=2)$ and cases lacking follow-up data after the index date $(n=103)$ were also excluded. ACS cases were identified using the diagnostic codes 410 and 411 of the ICD-9 and AF from the code 427.31. Pre-existing AF was defined as diagnosed AF occurring before ACS diagnosis. Newonset $\mathrm{AF}$ was defined as diagnosed AF occurring after or at the same time as ACS diagnosis. Diagnosis of AF was defined when it was a discharge diagnosis or was confirmed on at least two occasions in the outpatient department. The accuracy of AF diagnosis with this definition in Taiwan NHIRD has been validated in previous studies [12, 13].

\section{Compliance with Ethics Guidelines}

This study is based on de-identified data collected from a healthcare claims database and does not contain any studies with human participants or animals performed by any of the authors, therefore informed consent was not obtained. The study conformed to the principles of the Helsinki Declaration and the institutional review board of Chang Gung University approved the study protocol.

\section{Outcome Measures}

Adverse outcomes were mortality, HF, and ischemic stroke/systemic embolism (IS/SE); all were identified using hospital discharge diagnoses. HF was identified from codes 398.91, 422,425 , and 428; IS/SE was identified from codes 433-438, and 444. For each outcome 
analysis, we retrospectively searched claims back to 2000 to exclude patients who had a previous admission diagnosis of the same outcome. A flowchart demonstrating patient recruitment for the study is shown in Fig. 1.

\section{Statistical Analysis}

Categorical variables are presented as frequencies and percentages. Chi-square or Fisher's exact tests were used to compare groups. Continuous variables are presented as mean $\pm \mathrm{s}$ tandard deviation, and an analysis of variance was used to determine differences among groups. The risk of adverse outcomes including mortality, HF, and IS/SE was assessed using the Cox regression analysis with time-dependent covariates for new-onset and pre-existing $\mathrm{AF}$ exposures. The event-free survival curves were plotted by the adjusted survival estimate. Statistical significance was set at $p<0.05$ and all analyses were carried out using SAS 9.4.

\section{RESULTS}

\section{Patient Characteristics}

We identified 6663 patients newly diagnosed with ACS during the study period. The mean age of patients was 66.6 years, $67.8 \%$ were men,

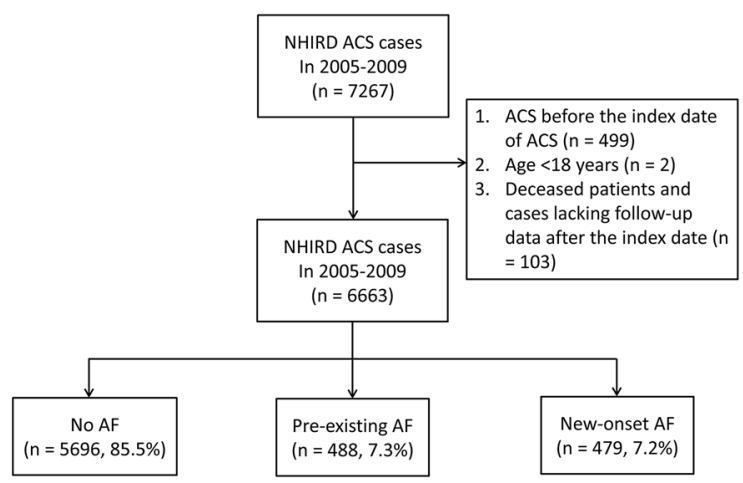

Fig. 1 Flow chart indicating the process of patient selection for the study. Pre-existing AF occurred before the diagnosis of ACS and new-onset AF occurred after or at the same time of ACS diagnosis. ACS acute coronary syndrome, $A F$ atrial fibrillation, NHIRD the National Health Insurance Research Database
40.2\% had diabetes mellitus, and $11.2 \%$ had a history of HF. New-onset AF was experienced by 479 (7.2\%) patients and 488 patients had preexisting AF (7.3\%). The remaining 5696 (85.5\%) patients did not have AF (no AF group). The baseline characteristics of the three groups are shown in Table 1. Compared to the no AF patients, those with pre-existing or new-onset AF were older, more likely to be women, to have history of hypertension, chronic pulmonary disease, and HF, and less likely to receive coronary revascularization and statin treatments. Compared to the patients with pre-existing AF, those with new-onset AF were less likely to have history of hypertension, hyperthyroidism, chronic kidney disease, chronic pulmonary disease, HF, ischemic stroke, and coronary revascularization. Those with new-onset $\mathrm{AF}$ were also more likely to receive coronary revascularization, anti-platelet, statin, and betablocker therapies than patients with pre-existing AF.

Compared to the no AF patients, patients with pre-existing or new-onset $\mathrm{AF}$ had a greater likelihood of death, HF, and IS/SE (Table 2). Although patients with new-onset AF had more favorable clinical features than those with preexisting $\mathrm{AF}$, the un-adjusted risks of death, HF, and IS/SE in patients with new-onset and preexisting AF were similar (Table 2). After adjusting for confounding variables (listed in Table 2), new-onset AF was significantly associated with higher risks of death [hazard ratio (HR) 1.51, 95\% confidence interval (CI) 1.31-1.74], HF (HR 1.72, 95\% CI 1.30-2.27), and IS/SE (HR 1.68, 95\% CI 1.26-2.23) compared to the no AF group. Pre-existing AF was associated with significantly higher risks of death (HR 1.19, 95\% CI 1.04-1.36) and HF (HR 1.57, 95\% CI 1.19-2.07), but not significant difference in the risk of IS/SE (HR 1.12, 95\% CI 0.82-1.53) than the no AF group. Compared to pre-existing AF, new-onset AF was significantly associated with a higher adjusted risk of death (HR 1.27, 95\% CI 1.06-1.52), or IS/SE (HR 1.49, 95\% CI 1.01-2.20), but no difference in the risk of $\mathrm{HF}$ (HR 1.09, 95\% CI 0.75-1.59). Figure 2 shows the adjusted event-free survival curves for death, $\mathrm{HF}$, and IS/SE after ACS. 
Table 1 Baseline characteristics of the study population

\begin{tabular}{|c|c|c|c|c|}
\hline & $\begin{array}{l}\text { All } \\
(n=6663)\end{array}$ & $\begin{array}{l}\text { No AF } \\
(n=5696)\end{array}$ & $\begin{array}{l}\text { Pre-existing AF } \\
(n=488)\end{array}$ & $\begin{array}{l}\text { New-onset AF } \\
(n=479)\end{array}$ \\
\hline Age (year) & $66.6 \pm 13.6$ & $65.4 \pm 13.6$ & $74.8 \pm 10.9^{a}$ & $72.3 \pm 11.7^{\mathrm{a}, \mathrm{b}}$ \\
\hline Male & $4520(67.8)$ & $3947(69.3)$ & $284(58.2)^{a}$ & $289(60.3)^{a}$ \\
\hline Diabetes mellitus & $2681(40.2)$ & $2269(39.8)$ & $213(43.6)$ & $199(41.5)$ \\
\hline Hypertension & $4779(71.7)$ & $3957(69.5)$ & $439(90.0)^{a}$ & $383(80.0)^{\mathrm{a}, \mathrm{b}}$ \\
\hline Dyslipidemia & $2790(41.9)$ & $2389(41.9)$ & $210(43)$ & $191(39.0)$ \\
\hline Hyperthyroidism & $103(1.6)$ & $69(1.2)$ & $27(5.5)^{\mathrm{a}}$ & $7(1.5)^{\mathrm{b}}$ \\
\hline Chronic kidney disease & $705(10.6)$ & $568(10.0)$ & $81(16.6)^{\mathrm{a}}$ & $56(11.7)^{\mathrm{b}}$ \\
\hline Chronic pulmonary disease & $2349(35.3)$ & $1883(33.1)$ & $269(55.1)^{a}$ & $197(41.1)^{\mathrm{a}, \mathrm{b}}$ \\
\hline History of heart failure & $749(11.2)$ & $493(8.7)$ & $192(39.3)^{\mathrm{a}}$ & $64(13.4)^{\mathrm{a}, \mathrm{b}}$ \\
\hline History of ischemic stroke & $708(10.6)$ & $537(9.4)$ & $116(23.8)^{\mathrm{a}}$ & $55(11.5)^{\mathrm{b}}$ \\
\hline $\begin{array}{l}\text { History of coronary } \\
\text { revascularization }\end{array}$ & $511(7.7)$ & $418(7.3)$ & $62(12.7)^{\mathrm{a}}$ & $31(6.5)^{\mathrm{b}}$ \\
\hline PCI & $3498(52.5)$ & $3108(54.6)$ & $167(34.2)^{\mathrm{a}}$ & $223(46.6)^{\mathrm{a}, \mathrm{b}}$ \\
\hline CABG & $542(8.1)$ & $475(8.3)$ & $20(4.1)^{\mathrm{a}}$ & $47(9.8)^{\mathrm{a}, \mathrm{b}}$ \\
\hline Mechanical heart valve & $41(0.6)$ & $25(0.4)$ & $9(1.8)^{\mathrm{a}}$ & $7(1.5)^{\mathrm{a}}$ \\
\hline Aspirin & $6232(93.5)$ & $5322(93.4)$ & $444(91.0)^{a}$ & $466(97.3)^{\mathrm{a}, \mathrm{b}}$ \\
\hline Clopidogrel & $5458(81.9)$ & $4711(82.7)$ & $355(72.8)^{\mathrm{a}}$ & $392(81.8)^{\mathrm{b}}$ \\
\hline Ticlopidine & $609(9.1)$ & $488(8.6)$ & $51(10.5)$ & $70(14.6)^{a, b}$ \\
\hline Statins & $4361(65.5)$ & $3842(67.5)$ & $229(46.9)^{a}$ & $290(60.5)^{\mathrm{a}, \mathrm{b}}$ \\
\hline Beta-blockers & $5198(78.0)$ & $4454(78.2)$ & $352(72.1)^{\mathrm{a}}$ & $392(81.8)^{\mathrm{b}}$ \\
\hline ACEI/ARBs & $5479(82.2)$ & $4673(82.0)$ & $387(79.3)$ & $419(87.5)^{\mathrm{a}, \mathrm{b}}$ \\
\hline Dual anti-platelets & $4895(74.8)$ & $4330(76)$ & $297(60.9)^{\mathrm{a}}$ & $358(74.7)^{\mathrm{b}}$ \\
\hline Warfarin & $480(7.2)$ & $273(4.8)$ & $111(22.8)^{\mathrm{a}}$ & $96(20.0)^{\mathrm{a}}$ \\
\hline $\mathrm{CHA}_{2} \mathrm{DS}_{2}$ VASc score $0-1$ & $934(14)$ & $897(15.8)$ & $6(1.2)^{\mathrm{a}}$ & $31(6.5)^{\mathrm{a}, \mathrm{b}}$ \\
\hline $\mathrm{CHA}_{2} \mathrm{DS}_{2} \mathrm{VASc}$ score $2-4$ & $3379(50.7)$ & $2986(52.4)$ & $170(34.8)^{\mathrm{a}}$ & $223(46.6)^{b}$ \\
\hline $\mathrm{CHA}_{2} \mathrm{DS}_{2}$ VASc score 5-9 & $2350(35.3)$ & $1813(31.8)$ & $312(63.9)^{a}$ & $225(47)^{\mathrm{a}, \mathrm{b}}$ \\
\hline
\end{tabular}

Data are shown as number (\%) or mean \pm standard deviation $A F$ atrial fibrillation, $P C I$ percutaneous coronary intervention, $C A B G$ coronary artery bypass surgery, $A C E I$ angiotensinconverting enzyme inhibitor, $A R B$ angiotensin receptor blocker

a Statistically significant differences between no AF and AF (either pre-existing or new-onset AF)

b Statistically significant differences between new-onset AF and pre-existing AF 
Table 2 Incidences of adverse outcomes and proportional hazard values from the Cox regression models

$\begin{array}{llll}\text { Events/person-year (\%) } & \begin{array}{l}\text { Non-adjusted model } \\ \text { Hazard ratio (95\% CI) }\end{array} & \begin{array}{l}\text { Adjusted model 1 } \\ \text { Hazard ratio (95\% CI) }\end{array} & \begin{array}{l}\text { Adjusted model 2 } \\ \text { Hazard ratio (95\% CI) }\end{array}\end{array}$

Death $^{\mathrm{a}}$

No AF 9.80

Pre-existing AF 22.63

New-onset AF 18.52

Heart failure ${ }^{\mathrm{b}}$

No AF

Pre-existing AF 10.99

New-onset AF $\quad 8.45$

Ischemic stroke/systemic embolism ${ }^{c}$

\begin{tabular}{ll} 
No AF & 3.00 \\
Pre-existing AF & 6.34 \\
New-onset AF & 5.04 \\
\hline
\end{tabular}

$$
\begin{gathered}
1 \text { (reference) } \\
2.12(1.87-2.41) \\
2.17(1.88-2.50)
\end{gathered}
$$

1 (reference)

$2.39(1.83-3.13)$

$2.21(1.68-2.91)$

1 (reference)

$2.01(1.50-2.68)$

$2.33(1.76-3.08)$

Hazard ratio (95\% CI)

Hazard ratio (95\% CI)

$A F$ atrial fibrillation, $C I$ confidence interval

a Adjusted for age, sex, hypertension, diabetes, dyslipidemia, chronic kidney disease, chronic pulmonary disease, ischemic stroke, coronary artery bypass surgery, percutaneous coronary revascularization, mechanical heart valve, without warfarin use, major bleeding, and statin use

b Adjusted for age, sex, hypertension, diabetes, dyslipidemia, chronic kidney disease, chronic pulmonary disease, ischemic stroke, coronary artery bypass surgery, percutaneous coronary intervention, mechanical heart valve, statin use, angiotensinconverting enzyme inhibitor/angiotensin receptor blocker use, and beta-blocker use

c Adjusted for age, sex, heart failure, diabetes, hypertension, dyslipidemia, mechanical heart valve, without warfarin use, and statin use
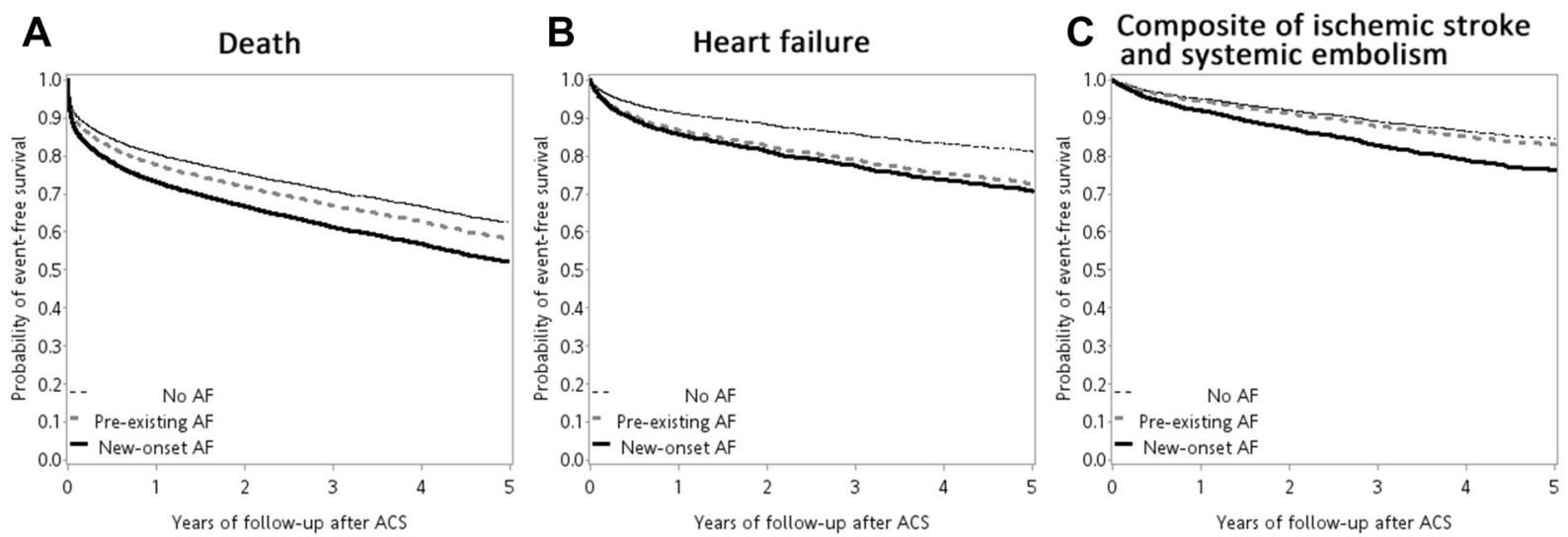

Fig. 2 Adjusted event-free survival curves for a death, b heart failure, c ischemic stroke/systemic embolism. $A C S$ acute coronary syndrome, $A F$ atrial fibrillation 
Data were divided into subgroups according to sex and age (Table 3). New-onset AF, rather than pre-existing $\mathrm{AF}$, was associated with a higher adjusted risk of death or IS/SE than no AF groups of men and women (Table 3). The associations between new-onset $\mathrm{AF}$ and adverse outcomes were consistently observed in elderly patients ( $\geq 65$ years), but less often in younger patients $(<65$ years). An interaction was detected between $\mathrm{AF}$ type and age with respect to the death outcome. In patients with age $<65 \mathrm{y} / \mathrm{o}$, the increased mortality risk was observed in patients with pre-existing AF (HR 1.89, 95\% CI 1.29-2.77) but not in patients with new-onset AF (HR 1.35; 95\% CI 0.85-2.17). Compared to younger patients with ACS, elderly ACS patients were more likely to have a history of diabetes mellitus, hypertension, chronic kidney disease, chronic pulmonary disease, HF, and ischemic stroke (Table 4). They were also less likely to receive percutaneous coronary intervention, anti-platelet, statin, and beta-blocker therapies.

\section{DISCUSSION}

In this study, we showed that, of patients who were hospitalized with a primary diagnosis of ACS for the first time, 7.3\% had pre-existing AF and $7.2 \%$ had new-onset AF. Although patients with new-onset AF had more favorable baseline characteristics than those with pre-existing $\mathrm{AF}$, the unadjusted risks of adverse outcomes were similar for both groups. After adjusting for

Table 3 Results of regressions between adverse outcomes and different AF types for subgroups of sex and age

\begin{tabular}{|c|c|c|c|}
\hline Subgroups & $\begin{array}{l}\text { Death } \\
\text { HR }(95 \% \text { CI })\end{array}$ & $\begin{array}{l}\text { Heart failure } \\
\text { HR (95\% CI) }\end{array}$ & $\begin{array}{l}\text { Ischemic stroke/systemic embolism } \\
\text { HR }(95 \% \mathrm{CI})\end{array}$ \\
\hline \multicolumn{4}{|l|}{ Male } \\
\hline No AF & 1 (reference) & 1 (reference) & 1 (reference) \\
\hline Pre-existing AF & $1.17(0.99-1.40)$ & $1.25(0.85-1.84)$ & $1.25(0.83-1.87)$ \\
\hline New-onset AF & $1.53(1.27-1.85)$ & $1.49(1.01-2.20)$ & $1.63(1.09-2.43)$ \\
\hline \multicolumn{4}{|l|}{ Female } \\
\hline No AF & 1 (reference) & 1 (reference) & 1 (reference) \\
\hline Pre-existing AF & $1.22(0.99-1.49)$ & $1.90(1.28-2.84)$ & $0.99(0.61-1.61)$ \\
\hline New-onset AF & $1.50(1.20-1.87)$ & $2.02(1.34-3.02)$ & $1.69(1.12-2.55)$ \\
\hline$p$ values for interaction & 0.856 & 0.305 & 0.628 \\
\hline \multicolumn{4}{|l|}{ Age $<65$ y/o } \\
\hline No AF & 1 (reference) & 1 (reference) & 1 (reference) \\
\hline Pre-existing AF & $1.89(1.29-2.77)$ & $2.26(1.14-4.48)$ & $1.16(0.46-2.88)$ \\
\hline New-onset AF & $1.35(0.85-2.17)$ & $1.77(0.90-3.49)$ & $1.61(0.77-3.37)$ \\
\hline \multicolumn{4}{|l|}{ Age $\geq 65 \mathrm{y} / \mathrm{o}$} \\
\hline No AF & 1 (reference) & 1 (reference) & 1 (reference) \\
\hline Pre-existing AF & $1.14(0.99-1.31)$ & $1.46(1.08-1.98)$ & $1.15(0.82-1.60)$ \\
\hline New-onset AF & $1.49(1.28-1.74)$ & $1.58(1.16-2.15)$ & $1.65(1.20-2.26)$ \\
\hline$p$ values for interaction & 0.005 & 0.772 & 0.987 \\
\hline
\end{tabular}

$A F$ atrial fibrillation, $C I$ confidence interval, $H R$ hazard ratio 
Table 4 Baseline characteristics divided by age group

\begin{tabular}{|c|c|c|c|}
\hline Variables & Age $<65$ y/o $(n=2879)$ & Age $\geq 65$ y/o $(n=3784)$ & $p$ value \\
\hline Age (years) & $53.4 \pm 8.0$ & $76.6 \pm 6.9$ & $<0.001$ \\
\hline Male & $2315(80.4)$ & $2205(58.3)$ & $<0.001$ \\
\hline Diabetes mellitus & $948(32.9)$ & $1733(45.8)$ & $<0.001$ \\
\hline Hypertension & $1589(55.2)$ & $3190(84.3)$ & $<0.001$ \\
\hline Dyslipidemia & $1117(38.8)$ & $1673(44.2)$ & $<0.001$ \\
\hline Hyperthyroidism & $48(1.7)$ & $55(1.5)$ & 0.548 \\
\hline Chronic kidney disease & $206(7.2)$ & $499(13.2)$ & $<0.001$ \\
\hline Chronic pulmonary disease & $581(20.2)$ & $1768(46.7)$ & $<0.001$ \\
\hline History of heart failure & $156(5.4)$ & $593(15.7)$ & $<0.001$ \\
\hline History of ischemic stroke & $153(5.3)$ & $555(14.7)$ & $<0.001$ \\
\hline History of coronary revascularization & $175(6.1)$ & $336(8.9)$ & $<0.001$ \\
\hline PCI & $1760(61.1)$ & $1738(45.9)$ & $<0.001$ \\
\hline CABG & $239(8.3)$ & $303(8.0)$ & 0.664 \\
\hline Mechanical heart valve & $17(0.6)$ & $24(0.6)$ & $<0.001$ \\
\hline Aspirin & $2750(95.5)$ & $3482(92.0)$ & $<0.001$ \\
\hline Clopidogrel & $2423(84.2)$ & $3035(80.2)$ & $<0.001$ \\
\hline Ticlopidine & $198(6.9)$ & $411(10.9)$ & $<0.001$ \\
\hline Statins & $2207(76.7)$ & $2154(56.9)$ & $<0.001$ \\
\hline Beta-blockers & $2449(85.1)$ & $2749(72.7)$ & $<0.001$ \\
\hline $\mathrm{ACEI} / \mathrm{ARBs}$ & $2397(83.3)$ & $3082(81.5)$ & 0.056 \\
\hline Dual anti-platelets & $2284(79.3)$ & $2701(71.4)$ & $<0.001$ \\
\hline Warfarin & $173(6.0)$ & $307(8.1)$ & $<0.001$ \\
\hline $\mathrm{CHA}_{2} \mathrm{DS}_{2} \mathrm{VASc}_{0-1}$ & $934(32.4)$ & $0(0)$ & $<0.001$ \\
\hline $\mathrm{CHA}_{2} \mathrm{DS}_{2}$ VASc $2-4$ & $1752(60.9)$ & $1627(43)$ & $<0.001$ \\
\hline $\mathrm{CHA}_{2} \mathrm{DS}_{2} \mathrm{VASc} 5-9$ & $193(6.7)$ & $2157(57)$ & $<0.001$ \\
\hline
\end{tabular}

Data were presented as mean $\pm \mathrm{SD}$ or no. (\%)

$A C E I$ angiotensin-converting enzyme inhibitors, $A R B s$ angiotensin receptor blockers, $C A B G$ coronary artery bypass surgery, $P C I$ percutaneous coronary intervention

confounding variables, new-onset AF confers a higher adjusted risk for death or IS/SE than preexisting AF. New-onset AF was significantly associated with a higher adjusted risk of adverse outcomes in both men and women. The significant associations between new-onset AF and adverse outcomes were more likely to be observed in elderly than younger patients with ACS. 
The prevalence rates of pre-existing and newonset AF in ACS patients differ among prior studies and range from 3.3 to $11.4 \%$ and 4.0 to $10.2 \%$, respectively $[1,5,11,14,15]$. In a prospective study of 2335 Sweden patients with ACS enrolled between 1995 and 2001, 442 of them had AF (18.9\%; pre-existing AF 8.7\%, newonset $A F 10.2 \%$ ) [16]. In contrast, the prevalence of $A F$ was much lower in the ARIAM registry [14]. Of the 39,237 ACS patients enrolled between 2001 and 2011, only 7.3\% had AF (preexisting AF 3.3\%, new-onset AF 4.0\%) [14]. In our study, the prevalence rates of pre-existing and new-onset $\mathrm{AF}$ fall within the range of $\mathrm{AF}$ prevalence in prior ACS studies and were similar to that in the Global Registry of Acute Coronary Events Study (GRACE) during the years 2000-2007 (pre-existing AF 7.6\%, new-onset AF $5.3 \%)$ [1].

AF leads to numerous unfavorable hemodynamic effects, such as loss of atrial contraction, rapid and irregular ventricular response, and loss of atrio-ventricular synchrony [17]. All of these factors lead to a decrease in cardiac output and an increase in left ventricular filling pressure [17]. Patients with pre-existing AF generally have greater cardiovascular disease burden and more co-morbidities than those without AF owing to AF being present for longer [18, 19]. In contrast, patients with new-onset AF were relatively younger and had fewer co-morbidities than patients with pre-existing AF $[4,15]$. Prior studies have shown that ACS patients with newonset AF were more likely to have higher peak creatine kinase levels, worse Killip class, higher heart rate, and more frequent reduced left ventricular ejection fraction than those with preexisting AF $[8,20]$. These unfavorable factors indirectly reflect more severe coronary artery disease and poorer myocardial function, which may explain the higher adjusted risk of mortality in ACS patients with new-onset AF than in those with pre-existing AF.

Results from previous studies evaluating the prognostic significance of pre-existing and newonset AF in patients with ACS are conflicting $[8-11,18,21]$. In a prospective multicenter study of 3393 patients with ACS, pre-existing AF was associated with a significantly higher risk of mortality (HR 1.4, 95\% CI 1.01-1.99) than no
AF, while new-onset AF was not [11]. Similar findings were observed in two other studies $[18,21]$. However, a greater number of studies have reported new-onset AF rather than preexisting AF results in a higher risk of mortality or adverse outcomes in patients with ACS $[4,8-10]$. For example, in a study of 6705 patients with ACS, the unadjusted in-hospital mortality risk was significantly higher in patients with pre-existing or new-onset AF than those without AF [9]. After adjusting for significant baseline variables, only the new-onset $\mathrm{AF}$ was associated with an increased risk of mortality [9]. Similarly in our unadjusted analyses, pre-existing and new-onset AF were both associated with a more than twofold increased risk of mortality or IS/SE. The increased risk of death or IS/SE associated with pre-existing AF was attenuated after multivariable adjustment. New-onset AF was independently associated with a higher risk of mortality or IS/SE than preexisting AF.

In the present study, we have found stronger associations between new-onset $\mathrm{AF}$ and adverse outcomes in the older patients than in the younger patients. There are several potential explanations for this finding. Greater left ventricular thickness, higher left ventricular filling pressure, and more depressed left ventricular function were more likely to occur in older patients than younger patients due to aging and a greater prevalence of diabetes mellitus, hypertension, and chronic kidney disease $[22,23]$. Compared to the younger patients, the morphological and functional characteristics of the heart in the older patients makes the elderly ACS patients more vulnerable to the unfavorable hemodynamic effects associated with newonset AF [24]. In addition, ACS patients with AF may also be predisposed to ventricular arrhythmia and stroke $[1,25]$. The underuse of beta-blockers and coronary revascularization in the older patients may amplify the unfavorable hemodynamic effects associated with new-onset AF in patients with ACS $[26,27]$.

The clinical implications of our findings are that ACS patients with AF, especially the elderly patients with new-onset $\mathrm{AF}$, should receive more attention in terms of prevention of adverse outcomes than those without AF. 
Similar to previous studies, age-related inequalities in ACS treatments are also recognized in this study. There remains a substantial opportunity to improve ACS outcomes especially in high-risk patients. An aggressive approach to ACS and AF management, including selective elective strategy, optimal use of P2Y12 inhibitor and non-vitamin $\mathrm{K}$ antagonist oral anticoagulant, or timely rhythm conversion is justified and should be balanced with the risk associated with aging and co-morbidity [28-30]. There is a growing need for randomized controlled trial data to be more representative of the elderly patients or patients with multiple co-morbidities. Careful selection of these highrisk patients for specific therapies and medication regimens may ultimately lead to better care of patients with these characteristics.

\section{Study Limitations}

We acknowledge some limitations to our study. Using diagnostic codes for less consistently reported outcomes such as HF and IS/SE can be significantly affected by the observation bias. We defined pre-existing $\mathrm{AF}$ as the $\mathrm{AF}$ that occurred before the index date of ACS. However, it is possible that patients with pre-existing AF could be falsely labeled as new-onset AF if patients had AF on the electrocardiogram but no prior AF diagnosis before the ACS event. In this retrospective cohort study of ACS patients, only $20-30 \%$ of patients with AF received oral anticoagulant therapy. The low usage of oral anticoagulants for patients with AF was probably related to an absence of guidelines for treating non-valvular AF during the study period and the bleeding concern associated with triple therapy. In the present study, $60.9 \%$ and $74.7 \%$ of patients with pre-existing and newonset AF were receiving dual-antiplatelet therapy. The circumstances have changed gradually in recent years. Compared to the years 2005-2009, oral anticoagulant, especially the non-vitamin-K antagonist oral anticoagulant, is more commonly used for non-valvular AF in recent years. Based on our results, ACS patients who develop new-onset $\mathrm{AF}$ is at high risk of long-term death and IS/SE especially in patients with age $\geq 65$ years. It is imperative to develop strategies to prevent AF onset and guidelines for initial aggressive treatment of new-onset AF in patients with ACS.

\section{CONCLUSIONS}

The un-adjusted risk of adverse outcomes in ACS patients with new-onset AF was similar to the risk of adverse outcomes in patients with pre-existing AF, even though patients with newonset $\mathrm{AF}$ displayed more favorable baseline characteristics. After adjusting for confounding variables, the presence of $\mathrm{AF}$ in patients with ACS, especially elderly patients with new-onset AF, was significantly associated with a higher risk of adverse outcomes than patients without AF.

\section{ACKNOWLEDGEMENTS}

We thank the assistance from the Research Services Center for Health Information, Chang Gung University, Taoyuan, Taiwan.

Funding. Sponsorship for this study and article processing charges were funded by the grant from the Chang Gung University (CMRP Grant number CIRPD1D0031), Taoyuan, Taiwan. All authors had full access to all of the data in this study and take complete responsibility for the integrity of the data and accuracy of the data analysis.

Editorial Assistance. We would like to thank Uni-edit (http://www.uni-edit.net) for editing and proofreading this manuscript.

Authorship. All named authors meet the International Committee of Medical Journal Editors (ICMJE) criteria for authorship for this article, take responsibility for the integrity of the work as a whole, and have given their approval for this version to be published.

Disclosures. Chun-Li Wang, Pei-Chun Chen, Hsiao-Ting Juang, and Chee-Jen Chang have nothing to disclose. 
Compliance with Ethics Guidelines. This study is based on de-identified data collected from a health care claims database and does not contain any studies with human participants or animals performed by any of the authors, therefore informed consent was not obtained. The study conformed to the principles of the Helsinki Declaration and the institutional review board of Chang Gung University approved the study protocol.

Data Availability. All data generated or analyzed during this study are included in this published article/as supplementary information files.

Open Access. This article is distributed under the terms of the Creative Commons Attribution-NonCommercial 4.0 International License (http://creativecommons.org/licenses/ by-nc/4.0/), which permits any noncommercial use, distribution, and reproduction in any medium, provided you give appropriate credit to the original author(s) and the source, provide a link to the Creative Commons license, and indicate if changes were made.

\section{REFERENCES}

1. McManus DD, Huang W, Domakonda KV, et al. Trends in atrial fibrillation in patients hospitalized with an acute coronary syndrome. Am J Med. 2012;125:1076-84.

2. Schmitt J, Duray G, Gersh BJ, Hohnloser SH. Atrial fibrillation in acute myocardial infarction: a systematic review of the incidence, clinical features and prognostic implications. Eur Heart J. 2009;30:1038-45.

3. Asanin M, Perunicic J, Mrdovic I, et al. Prognostic significance of new atrial fibrillation and its relation to heart failure following acute myocardial infarction. Eur J Heart Fail. 2005;7:671-6.

4. Morishima I, Tomomatsu T, Okumura K, et al. Newonset atrial fibrillation may be a more important predictor of cardiac mortality in acute myocardial infarction patients than preexisting atrial fibrillation. Int J Cardiol. 2015;187:475-7.

5. Poci D, Hartford M, Karlsson T, et al. Role of the CHADS2 score in acute coronary syndromes: risk of subsequent death or stroke in patients with and without atrial fibrillation. Chest. 2012;141:1431-40.

6. Bengtson LG, Chen LY, Chamberlain AM, et al. Temporal trends in the occurrence and outcomes of atrial fibrillation in patients with acute myocardial infarction (from the Atherosclerosis Risk in Communities Surveillance Study). Am J Cardiol. 2014;114:692-7.

7. Hersi A, Alhabib KF, Alsheikh-Ali AA, et al. Prognostic significance of prevalent and incident atrial fibrillation among patients hospitalized with acute coronary syndrome: findings from the Gulf RACE-2 Registry. Angiology. 2012;63:466-71.

8. Crenshaw BS, Ward SR, Granger CB, et al. Atrial fibrillation in the setting of acute myocardial infarction: the GUSTO-I experience. Global utilization of streptokinase and TPA for occluded coronary arteries. J Am Coll Cardiol. 1997;30:406-13.

9. Gonzalez-Pacheco H, Marquez MF, Arias-Mendoza A, et al. Clinical features and in-hospital mortality associated with different types of atrial fibrillation in patients with acute coronary syndrome with and without ST elevation. J Cardiol. 2015;66:148-54.

10. Mehta RH, Dabbous OH, Granger CB, et al. Comparison of outcomes of patients with acute coronary syndromes with and without atrial fibrillation. Am J Cardiol. 2003;92:1031-6.

11. Lau DH, Huynh LT, Chew DP, et al. Prognostic impact of types of atrial fibrillation in acute coronary syndromes. Am J Cardiol. 2009;104:1317-23.

12. Chang $\mathrm{CH}$, Lee YC, Tsai CT, et al. Continuation of statin therapy and a decreased risk of atrial fibrillation/flutter in patients with and without chronic kidney disease. Atherosclerosis. 2014;232:224-30.

13. Lin LJ, Cheng $\mathrm{MH}$, Lee $\mathrm{CH}$, et al. Compliance with antithrombotic prescribing guidelines for patients with atrial fibrillation-a nationwide descriptive study in Taiwan. Clin Ther. 2008;30:1726-36.

14. Almendro-Delia M, Valle-Caballero MJ, Garcia-Rubira JC, et al. Prognostic impact of atrial fibrillation in acute coronary syndromes: results from the ARIAM registry. Eur Heart J Acute Cardiovasc Care. 2014;3:141-8.

15. Braga CG, Ramos V, Martins J, et al. Impact of atrial fibrillation type during acute coronary syndromes: clinical features and prognosis. Rev Port Cardiol. 2015;34:403-10.

16. Poci D, Hartford M, Karlsson T, Edvardsson N, Caidahl K. Effect of new versus known versus no atrial fibrillation on 30-day and 10-year mortality in 
patients with acute coronary syndrome. Am J Cardiol. 2012;110:217-21.

17. Clark DM, Plumb VJ, Epstein AE, Kay GN. Hemodynamic effects of an irregular sequence of ventricular cycle lengths during atrial fibrillation. J Am Coll Cardiol. 1997;30:1039-45.

18. Maagh P, Butz T, Wickenbrock I, et al. New-onset versus chronic atrial fibrillation in acute myocardial infarction: differences in short- and long-term follow-up. Clin Res Cardiol. 2011;100:167-75.

19. Gamst J, Christiansen CF, Rasmussen BS, Rasmussen LH, Thomsen RW. Pre-existing atrial fibrillation and risk of arterial thromboembolism and death following pneumonia: a population-based cohort study. BMJ Open. 2014;4:e006486.

20. Galvao Braga C, Ramos V, Vieira C, et al. New-onset atrial fibrillation during acute coronary syndromes: predictors and prognosis. Rev Port Cardiol. 2014;33:281-7.

21. Podolecki T, Lenarczyk R, Kowalczyk J, et al. Effect of type of atrial fibrillation on prognosis in acute myocardial infarction treated invasively. Am J Cardiol. 2012;109:1689-93.

22. Letachowicz K, Boratynska M, Obremska M, et al. Prevalence of left ventricular hypertrophy and left ventricular dysfunction in older renal transplant recipients. Transplant Proc. 2016;48:1641-3.

23. Raymond I, Pedersen F, Steensgaard-Hansen F, et al. Prevalence of impaired left ventricular systolic function and heart failure in a middle aged and elderly urban population segment of Copenhagen. Heart. 2003;89:1422-9.
24. Dai X, Busby-Whitehead J, Alexander KP. Acute coronary syndrome in the older adults. J Geriatr Cardiol. 2016;13:101-8.

25. Gorenek B, Blomstrom Lundqvist C, Brugada Terradellas J, et al. Cardiac arrhythmias in acute coronary syndromes: position paper from the joint EHRA, ACCA, and EAPCI task force. EuroIntervention. 2015;10:1095-108.

26. Soumerai SB, McLaughlin TJ, Spiegelman D, et al. Adverse outcomes of underuse of beta-blockers in elderly survivors of acute myocardial infarction. JAMA. 1997;277:115-21.

27. Gustafsson I, Hvelplund A, Hansen KW, et al. Underuse of an invasive strategy for patients with diabetes with acute coronary syndrome: a nationwide study. Open Heart. 2015;2:e000165.

28. Lip GY, Windecker S, Huber K, et al. Management of antithrombotic therapy in atrial fibrillation patients presenting with acute coronary syndrome and/or undergoing percutaneous coronary or valve interventions: a joint consensus document of the European Society of Cardiology Working Group on Thrombosis, European Heart Rhythm Association (EHRA), European Association of Percutaneous Cardiovascular Interventions (EAPCI) and European Association of Acute Cardiac Care (ACCA) endorsed by the Heart Rhythm Society (HRS) and Asia-Pacific Heart Rhythm Society (APHRS). Eur Heart J. 2014;35:3155-79.

29. Gibson CM, Mehran R, Bode C, et al. Prevention of bleeding in patients with atrial fibrillation undergoing PCI. N Engl J Med. 2016;375:2423-34.

30. Hoedemaker NPG, Damman P, Woudstra P, et al. Early invasive versus selective strategy for non-STsegment elevation acute coronary syndrome: the ICTUS trial. J Am Coll Cardiol. 2017;69:1883-93. 